\title{
NOTAS DE JURISPRUDENCIA CONTENCIOSO-ADMINISTRATIVA
}

\author{
TOMÀS FONT I LLOVET \\ ALEXANDRE PEÑALVER I CABRÉ \\ FRANCESC RODRÍGUEZ PONTÓN \\ JOAQUÍN TORNOS MAS \\ Universidad de Barcelona \\ jtornos@tornosabogados.com
}

Cómo citar/Citation

Font i Llovet, T., Peñalver i Cabré, A., Rodríguez Pontón, F. y Tornos Mas, J. (2017).

Notas de jurisprudencia contencioso-administrativa.

Revista de Administración Pública, 203, 267-289.

doi: https://doi.org/10.18042/cepc/rap.203.09

\section{SUMARIO}

I. RECURSO CASACIONAL CONTRA SENTENCIAS DE LOS JUZGADOS. ALGUNOS CRITERIOS DE INTERÉS PARA SU ADMISIÓN. II. ¿ SUBSISTE EL RECURSO CASACIONAL AUTONÓMICO? LA DOCTRINA DEL TRIBUNAL SUPERIOR DE JUSTICIA DE CATALUÑA. III. EL PROCEDIMIENTO DE CORTE DEL SUMINISTRO DE GAS Y ELECTRICIDAD. IV. LOS INFORMES TÉCNICO-ECONÓMICOS PRECEPTIVOS EN LAS ORDENANZAS FISCALES: IMPARCIALIDAD, OBJETIVIDAD Y CRITERIO PROPIO DE LA ADMINISTRACIÓN: 1. Servicio público y potestad normativa municipal. 2. El planteamiento de las sentencias del TSJ y del TS: preceptividad, imparcialidad, objetividad, criterio propio de la Administración. 3. El carácter preceptivo del informe técnico-económico. 4. El informe debe ser propio de la Administración. 4.1. Informe propio, objetividad e imparcialidad. 4.2. El caso de la «externalización» de las mesas de contratación. 5. Informe técnico-económico y ejercicio de funciones públicas. V. UN PASO MÁS EN EL CONTROL JUDICIAL DE LA EXISTENCIA DE SUFICIENTES RECURSOS HÍDRICOS PARA NUEVAS DEMANDAS PREVISTAS POR EL PLANEAMIENTO URBANÍSTICO. 


\section{RECURSO CASACIONAL CONTRA SENTENCIAS DE LOS JUZGADOS. ALGUNOS CRITERIOS DE INTERÉS PARA SU ADMISIÓN}

La nueva regulación del recurso de casación está planteando una larga serie de cuestiones conflictivas que los autos del Tribunal Supremo van resolviendo, creando así un cuerpo de doctrina judicial que va balizando el proceloso terreno por el que en la actualidad los abogados deben transitar cuando deciden interponer un recurso casacional.

Por esta razón queremos destacar, a modo de ejemplo de estas resoluciones del Tribunal Supremo, el Auto de 13 de marzo de 2017, número de recurso 313/2016, en el que se resuelve la admisión de un recurso de casación frente a una sentencia de un juzgado contencioso-administrativo.

El acto impugnado ante el Juzgado contencioso administrativo $\mathrm{n}^{\circ} 15$ de Barcelona fue una sanción impuesta, por la Generalidad de Cataluña, a la mercantil UBER BV por la contratación como transportista, o la facturación en nombre propio, de servicios de transporte público discrecional de viajeros en vehículos de hasta 9 plazas sin ser previamente titular de autorización de transporte.

El Juzgado estimó el recurso al entender que la actividad desarrollada por UBER BV no era una actividad de transporte, sujeta a esta legislación sectorial, sino, por el contrario, una actividad encuadrable en la normativa propia de servicios de la sociedad de la información. Consecuentemente anuló la sanción.

La Generalidad de Cataluña interpuso recurso de casación, y el Tribunal Supremo en el auto citado resuelve la admisión del mismo. No nos importa ahora entrar en la compleja y debatida cuestión de fondo, aunque sí debemos recordar que el abogado general Szpunar, en su informe incluido en el procedimiento por cuestión prejudicial que se tramita ante el Tribunal de Luxemburgo sobre esta cuestión, afirma el 11 de mayo de 2017 que «a pesar de ser un concepto innovador, la plataforma electrónica UBER pertenece al ámbito del transporte, de modo que puede obligarse a UBER a disponer de las licencias y autorizaciones requeridas por el derecho nacional». Pero de acuerdo con lo antes señalado, al margen ahora de la cuestión de fondo que en su día resuelva el Tribunal Supremo, en este breve comentario nos parece de interés dar cuenta de los argumentos que en este caso utiliza el Tribunal Supremo para admitir el recurso casacional.

El recurso se plantea ante una sentencia de un juzgado contencioso-administrativo. El art. 86,1 de la ley jurisdiccional establece que únicamente serán susceptibles de recurso de casación las sentencias de los juzgados que contengan doctrina que se repute gravemente dańosa para los intereses generales y sean susceptibles de extensión de efectos. 
Pues bien, el auto que comentamos nos da las siguientes indicaciones de interés en la interpretación de este precepto. La verificación de la concurrencia del presupuesto de que se trate de una sentencia susceptible de extensión de efectos requiere la integración de lo dispuesto en el art. 86,1 de la LJCA con la regulación contenida en el art. 110 de la misma ley. En el caso enjuiciado, dado que la multa impuesta lo es a una empresa que lleva a cabo una actividad económica, sin entrar de momento en la cuestión de fondo de si se trata de actividad o no de transporte, se entiende que el acto recurrido incide en la unidad de mercado. Así, se nos dice que el litigio plantea el régimen aplicable a la actividad que lleva a cabo UBER y, consecuentemente, al ejercicio de la libre prestación de servicios, materia íntimamente conexa con la garantía de la unidad de mercado.

Por tanto, la materia «unidad de mercado» puede convertirse en un ámbito material que permita sostener con cierta amplitud la interposición de recursos casacionales frente a sentencias de los juzgados. Toda actuación administrativa que regule el ejercicio de actividades económicas, o que intervenga sobre las mismas, podrá entenderse que afecta a la libre prestación de servicios y, por tanto, a la unidad de mercado. De este modo se podrá justificar que se cumple con uno de los presupuestos de la admisión de la casación. Como ocurre en este caso, una sanción en materia de transportes puede cumplir el requisito de dar lugar a una sentencia susceptible de extensión de efectos.

La segunda referencia de interés del auto comentado es su valoración sobre la concurrencia del interés casacional. Sobre este punto, el auto afirma lo siguiente:

La cuestión jurídica que se plantea en casación es, por tanto, la de determinar si una actividad como la descrita se enmarca en el ámbito de la normativa de transportes —que exige el previo título habilitante para su ejercicio- o si, por el contrario, sus particulares características la sitúan en el ámbito de la LSSI y, en última instancia, en el ámbito de la Directiva de Servicios —en el que la premisa de partida es el libre establecimiento y la libre prestación de servicios-. Así formulada, la cuestión reviste interés casacional objetivo para la formación de la jurisprudencia, pues exige un pronunciamiento sobre un problema jurídico que trasciende del caso, que ha suscitado el planteamiento de diversas cuestiones prejudiciales ante el Tribunal de Justicia de la Unión Europea —entre ellas, la formulada por el Juzgado de lo Mercantil núm. 3 de Barcelona - y sobre el que no existe jurisprudencia de esta Sala (JT).

\section{II. ¿̇SUBSISTE EL RECURSO CASACIONAL AUTONÓMICO? LA DOCTRINA DEL TRIBUNAL SUPERIOR DE JUSTICIA DE CATALUÑA}

La reforma del recurso de casación en el orden contencioso administrativo, acometida por la Ley Orgánica 7/2015, como hemos apuntado en el 
anterior comentario, está dando lugar a problemas interpretativos de notable importancia. Uno de estos problemas afecta a la determinación de si, una vez suprimidos los recursos de casación para unificación de doctrina y en interés de la ley, también debe entenderse suprimida la llamada casación autonómica cuando se trata de impugnar sentencias de los Tribunales Superiores de Justicia que aplican derecho autonómico.

La cuestión ha sido resuelta en diversos autos del Tribunal Superior de Justicia de Cataluña, Autos números 3, 5 y 8 de 10 de mayo de 2017, concretamente por la sección de casación de la Sala de lo Contencioso-Administrativo. Presentados sendos escritos en preparación del recurso de casación frente a sentencias del propio Tribunal Superior de Justicia se acuerda declarar su inadmisión al haber dejado de existir el recurso de casación autonómico frente a estas sentencias. Veamos los argumentos que va desgranado el Tribunal para fundar su decisión final.

Primer argumento. El recurso de casación ante los Tribunales Superiores de Justicia frente a sentencias del mismo tribunal no está contemplado en la legislación procesal. El art. 86,1 de la LJCA únicamente define las resoluciones recurribles en casación ante el Tribunal Supremo al establecer que las sentencias dictadas en única instancia por los Juzgados de lo ContenciosoAdministrativo y las dictadas en única instancia o en apelación por la Sala de lo Contencioso-Administrativo de la Audiencia Nacional y por las Salas de lo Contencioso-Administrativo de los Tribunales Superiores de Justicia serán susceptibles de recurso de casación ante la Sala de lo Contencioso-Administrativo del Tribunal Supremo.

Por tanto, no existe previsión alguna en cuanto a la definición de las sentencias recurribles en casación por infracción de norma autonómica ante las Secciones de Casación de las Salas de lo Contencioso-Administrativo de los Tribunales Superiores de Justicia.

Segundo argumento. Las únicas referencias a la casación autonómica son las recogidas en los párrafos segundo y tercero del art. 86.3 LJCA, cuya naturaleza de regulación orgánica, si bien contenida en una norma procesal, es evidente.

Tercer argumento. La interpretación sistemática del art. 86 de la LJCA obliga a entender que las disposiciones orgánicas contenidas en los párrafos 2 y 3 del número tercero del citado artículo se refieren al único recurso de casación del que puede conocer la Sección que en dichos párrafos se regula: el recurso de casación contra las sentencias dictadas en única instancia por los Juzgados de lo Contencioso-Administrativo que contengan doctrina que se repute gravemente dañosa para los intereses generales, sean susceptibles de extensión de efectos, y se funde en normas emanadas de la comunidad autónoma. 
Cuarto argumento. Una correcta delimitación de la recurribilidad de las sentencias dictadas por las Salas de los TSJ debe partir de la posición constitucional de los Tribunales Superiores de Justicia como órgano que culmina la organización judicial en el ámbito territorial de la comunidad autónoma, art. 152,1 CE, de forma análoga a la posición del Tribunal Supremo en materia de derecho estatal.

Los Tribunales Superiores de Justicia, a través en su caso de sus Secciones especializadas por las normas de reparto, son quienes cumplen la función de formar la jurisprudencia en materia de derecho autonómico. Por ello, una vez suprimido el recurso de casación para unificación de doctrina, las sentencias dictadas por las Salas de lo Contencioso-Administrativo de los TSJ en aplicación del derecho autonómico no son susceptibles de recurso, al igual que sucede con las sentencias dictadas por el Tribunal Supremo en aplicación del derecho estatal.

Quinto argumento. La casación introducida por la LO 7/2015 ante el Tribunal Supremo responde a la lógica de dos Secciones: una de admisión (no especializada), que se limita a examinar si concurren los requisitos de admisión, y otra de resolución (especializada), que es la que forma jurisprudencia. Una eventual aceptación de una casación autonómica contra sentencias dictadas por la misma Sala sería antinómica con este diseño casacional, pues la Sección que dicta la resolución que se recurre (generalmente especializada) vería revisada su interpretación por la Sección de casación del art. 86.3 LJCA (no especializada y rotatoria), al tener ésta competencia tanto para admitir como para resolver.

Sexto argumento. La reforma del art. 264 de la Ley Orgánica del Poder Judicial supone que el Pleno jurisdiccional es el medio para unificar criterios «especialmente en los casos en que los Magistrados de las diversas Secciones de una misma Sala o Tribunal sostuvieren en sus resoluciones diversidad de criterios interpretativos en la aplicación de la ley en asuntos sustancialmente iguales». Por tanto, la existencia de una Sección de Casación, con prevalencia funcional sobre las demás salas y secciones del mismo tribunal, no solo carece de soporte en la legislación orgánica judicial, sino que sería contradictoria con la nueva regulación introducida por el art. 264 de la LOPJ.

$\mathrm{Al}$ final se concluye que teniendo en cuenta que la jurisprudencia sobre el derecho autonómico ya está formada por las resoluciones dictadas por las Salas territoriales y Secciones especializadas del TSJ, debe afirmarse que la reforma de 2015 no incluye a las sentencias dictadas por las Salas de los TSJ en el ámbito del recurso de casación autonómico, sin perjuicio de que sí se incluyan las de los juzgados. La doctrina fundada de los autos citados llega, pues, a una conclusión relevante, que desconocemos si es compartida por otros Tribunales Superiores de Justicia (JT). 


\section{EL PROCEDIMIENTO DE CORTE DEL SUMINISTRO DE GAS Y ELECTRICIDAD}

Las empresas privadas prestadoras de servicios económicos de interés general, aun actuando en un mercado liberalizado, están sujetas a una intensa regulación y a obligaciones de servicio público. El interés general vinculado a la prestación que llevan a cabo estas empresas privadas justifica esta presencia reguladora así como la imposición de obligaciones de servicio público. Este es el caso de las empresas suministradoras de electricidad y gas, servicios esenciales para que los ciudadanos puedan llevar a cabo una vida digna en sus hogares. Por esta razón, la relación comercial con los usuarios está regulada, estableciéndose en este sentido el procedimiento para llevar a cabo el corte del suministro por impago. También se impone como obligación de servicio público el mantenimiento del suministro aun en caso de impago si se trata de unidades familiares en situación de pobreza energética.

La Sentencia del Tribunal Supremo 411/2017 de 9 de marzo, recurso de casación 4155/2014, confirma la sanción de 1000000 de euros impuesta por la Orden de la Consejería de Economía y Hacienda de la Comunidad Autónoma de Madrid a Gas Natural Sur SDG, SA, al haber llevado a cabo el corte de suministro de gas sin haber seguido el procedimiento establecido. La sentencia nos parece relevante, más allá de por las cuestiones jurídicas resueltas en la misma, en la medida que pone de relieve la importancia de la regulación administrativa en las relaciones comerciales privadas y la gravedad de las sanciones que pueden imponerse como derecho garantizador del marco regulador exigible a las empresas suministradoras.

El procedimiento para llevar a cabo el corte de suministro está regulado en el art. 57 del RD 1434/2002 de 27 de diciembre:

La empresa distribuidora podrá suspender el suministro a consumidores privados a tarifa cuando hayan transcurrido al menos dos meses desde que les hubiera sido requerido fehacientemente el pago, sin que el mismo se hubiera hecho efectivo. A estos efectos, el requerimiento se practicará mediante remisión, a la dirección que a efectos de comunicación figure en el contrato de suministro a tarifa, por cualquier medio que permita tener constancia de la recepción por el interesado o su representante, así como de la fecha, identidad y contenido del mismo, quedando la empresa distribuidora obligada a conservar en su poder la acreditación de la notificación efectuada. En el supuesto de rechazo de la notificación, se especificarán las circunstancias del intento de notificación y se tendrá por efectuado el trámite. Dicha comunicación deberá incluir el trámite de interrupción del suministro por impago, precisando la fecha a partir de la que se interrumpirá, de no abonarse en fecha anterior las cantidades adeudadas. 
El debate sobre la validez de la sanción impuesta se centra en tres cuestiones: si existió o no una notificación fehaciente a la persona afectada por el corte de suministro, si en la notificación se indicó la fecha concreta en que debería llevarse a cabo el corte, y sobre la proporcionalidad de la sanción impuesta.

Respecto de la primera cuestión, la notificación, la recurrente alega que se enviaron diversas cartas a la persona afectada por el corte. Frente a ello, el Tribunal alega que no consta la recepción de las mismas, por lo que la notificación no es fehaciente. Si bien se reconoce que la empresa privada no posee los medios de las administraciones para proceder a las notificaciones de forma que quede constancia de su recepción, se afirma que Gas Natural debió notificar por correo certificado o mediante burofax, lo que le hubiera permitido tener constancia de la recepción de sus cartas.

Respecto a la obligación de precisar la fecha del corte, la sentencia de instancia entendió que la referencia del art. 57 a tener que precisar «la fecha a partir de la que se interrumpió» exige indicar el día concreto en que se llevará a cabo el corte de suministro, cosa que no se hacía en la notificación. El Tribunal Supremo confirma la interpretación del art. 57 llevada a cabo por el TSJ. En este sentido afirma que:

En primer lugar, la interpretación gramatical que ofrece la recurrente omite el hecho de que la acción que ha de desarrollarse a partir de una fecha determinada es la interrupción del suministro, lo cual no constituye una acción instantánea, sino mantenida en el tiempo. Por tanto, la expresión «la fecha a partir de la que se interrumpirá» está haciendo referencia al día en que comienza el corte del suministro, esto es, al día en que tiene lugar la desconexión de la red, y no al día a partir del cual la empresa suministradora puede realizarla.

En segundo lugar, el artículo 57 del Real Decreto 1434/2002 no agota en su número 1 los elementos útiles para interpretar aquellos términos. El número 3 establece: «Para proceder a la suspensión del suministro por impago, la empresa distribuidora no podrá señalar como día para la interrupción un día festivo ni aquéllos que, por cualquier motivo, no exista servicio de atención al cliente tanto comercial como técnica a efectos de la reposición del suministro, ni en víspera de aquellos días en que se dé alguna de estas circunstancias».

De esta última especificación se desprende sin duda que la fecha que ha de comunicarse al usuario es el día cierto y determinado en que comenzará a verse privado de gas. La norma exige señalar un día para la interrupción, lo que equivale a consignar un concreto día y no un plazo indefinido a partir de una fecha.

Una vez se aprecia la vulneración de lo dispuesto en el art. 57, la conducta se califica como infracción grave, según el art. 110,5 de la Ley 34/1998 de 7 de octubre: «[...] el incumplimiento de cuantas obligaciones formales 
se impongan a quienes realicen actividades de suministro al público de productos petrolíferos o gases combustibles por canalización en garantía de los derechos de los consumidores y usuarios». A este tipo le puede corresponder una sanción de hasta 6000000 de euros.

La sanción de 1000000 de euros se estima proporcionada, atendiendo a uno de los elementos que el art. 112 de la ley citada establece para graduar las sanciones: la intencionalidad. En este sentido, la sentencia afirma que:

[...] como acertadamente considera la Sala «a quo», para graduar la sanción se ha tenido en cuenta la intencionalidad en la comisión de la infracción, pues la interesada, como entidad distribuidora de gas natural con dilatada experiencia, ha ocasionado perjuicios a los usuarios impidiendo el ejercicio de los derechos de los mismos, existiendo intencionalidad en la comisión de la infracción, habida cuenta de aquella característica de la empresa que debe conocer el procedimiento en cuestión y que además había sido advertida de tal necesario cumplimiento, pese a lo cual siguió sin cumplimentarlo, habiéndose impuesto la sanción en grado mínimo.

En definitiva, como vemos, la actividad de las empresas suministradoras de gas y electricidad está sujeta a un marco regulador que protege de forma importante a los consumidores, imponiendo a las empresas privadas un procedimiento de actuación riguroso para poder llevar a cabo el corte de suministro en caso de impago. El incumplimiento de defectos formales (notificación no fehaciente o señalamiento de la fecha a partir de la cual se llevará a cabo el corte en lugar de indicar la fecha concreta del corte) puede dar lugar a una sanción de 1000000 de euros (JT).

\section{LOS INFORMES TÉCNICO-ECONÓMICOS PRECEPTIVOS EN LAS ORDENANZAS FISCALES: IMPARCIALIDAD, OBJETIVIDAD Y CRITERIO PROPIO DE LA ADMINISTRACIÓN}

\section{SERVICIO PÚBLICO Y POTESTAD NORMATIVA MUNICIPAL}

El debate en torno a los servicios públicos municipales ha retomado actualidad bajo muy diversas perspectivas. Desde su sostenibilidad hasta la delimitación de su nivel óptimo de prestación, desde sus modos de gestión hasta su financiación y hasta su incidencia en los derechos sociales. El trasfondo ideológico que subyace en la dialéctica de la denominada -imprecisamente- «remunicipalización» de los servicios municipales ha ayudado a mantener vivo el debate sobre estas cuestiones.

Uno de los aspectos que son objeto de cuestionamiento es el de la justificación de los costes de los servicios locales, ya sea en cuanto a su sostenibilidad 
o la de la concreta forma de gestión de que se trate (LRSAL), ya sea en la medida que deba producirse la traslación de dichos costes a los usuarios mediante la imposición de la tasa correspondiente.

Por su parte, la potestad normativa municipal, que se expresa a través de la aprobación de las ordenanzas, incluidas las fiscales, contiene un fuerte componente político en tanto es expresión autónoma de las opciones de gobierno que cuentan con el apoyo mayoritario de la corporación. Pero ello no es óbice para que la amplísima discrecionalidad que caracteriza a la potestad normativa deba sujetarse a determinados elementos reglados, formales y materiales, que delimitan aquella discrecionalidad.

En este sentido resulta de gran interés el análisis de aquellos elementos que el ordenamiento ha previsto para fundamentar materialmente el establecimiento o modificación de las tasas por la prestación de los servicios municipales. Los informes técnico-económicos preceptivos para la aprobación de las ordenanzas fiscales son uno de los más relevantes.

\section{EL PLANTEAMIENTO DE LAS SENTENCIAS DEL TSJ Y DEL TS: PRECEPTIVIDAD, IMPARCIALIDAD, OBJETIVIDAD, CRITERIO PROPIO DE LA ADMINISTRACIÓN}

Es objeto de este comentario la STS de 26 de abril de 2017, rec. 167/2016, ponente Martínez Mico, que resuelve en sentido desestimatorio el recurso de casación interpuesto por el Ayuntamiento de León y por la Sociedad Mixta Aguas de León contra la Sentencia del Tribunal Superior de Justicia de Castilla y León (Valladolid) 1765/2015, de 24 de julio (ponente: Picón Palacio), que estimaba parcialmente la demanda presentada por la Asociación de la Cámara de la Propiedad Urbana de León y Provincia y en la que se impugnaba el «Acuerdo Definitivo de establecimiento y/o modificación de las Ordenanzas Fiscales reguladoras de las Tasas Municipales, adoptado por el Pleno del Ayuntamiento de León, en sesión celebrada el 20 de diciembre de 2013, en lo relativo al establecimiento de nuevas Tasas, actualización de las existentes y modificación de la Ordenanza reguladora de las Tasas por Suministro de Agua Potable y Servicios Complementarios y en lo relativo al establecimiento de nuevas Tasas, actualización de las existentes y modificación de la Ordenanza reguladora de las Tasas de Alcantarillado", publicado en el BOP de León de 26 de diciembre de 2013. Se trata de una sentencia sobre un asunto de contenido complejo en sus detalles, como muestra el hecho de que la del TSJ tuvo que ser aclarada por auto de 30 de noviembre de 2015 . Y es una sentencia cuya importancia queremos destacar desde la perspectiva, no solo del contenido de la regulación de una tasa y sus elementos, sino desde la que implica valorar el carácter preceptivo de determinados informes y sus condiciones de imparcialidad y objetividad, un 
asunto que encuentra unas condiciones idóneas en este contexto; pero que lo trasciende, como intentaremos también mostrar.

Para intentar exponer con la máxima claridad el tema, conviene partir de las premisas y de las respuestas que dio el TSJ de Castilla y León en su sentencia de 2015, bastante más breve que la posterior del TS ahora comentada. Para ello distinguiremos, en cuanto al contenido de fondo de la sentencia del TSJ-CyL, la delimitación precisa del objeto impugnado, tres premisas, dos razonamientos clave y el fallo.

La delimitación precisa del objeto se indica en el FJ tercero:

Son, pues, el establecimiento de nuevas tasas, actualización de las existentes y modificación de la «Ordenanza Reguladora de las Tasas por Suministros de Agua Potable y Servicios Complementarios» — concretadas en la cuantía de 50 euros por cambio de titular del contrato de suministro en los casos de arrendamiento y de subrogación, recogido en dos párrafos del artículo 9, tarifa 4 a —; el establecimiento de una nueva tasa por la conservación de acometidas de agua potable y la tasa por conservación de contadores —en la tarifa $7^{\text {a }}$ del artículo 9 de la Ordenanza Fiscal - y el establecimiento de nuevas tasas, actualización de las existentes y modificación de la «Ordenanza Fiscal Reguladora de las Tasas de Alcantarillado» - concretadas en el establecimiento de una nueva tasa por la conservación de acometidas de saneamiento en la redacción del artículo 5 de la Ordenanza Fiscal Reguladora de las Tasas de Alcantarillado; el establecimiento de una nueva tasa por otros usos a los titulares de pozos o sondeos existentes en el interior de las fincas, en la redacción del artículo 4. d ) de la Ordenanza, y el incremento del $1,5 \%$ de las tarifas del artículo 5 de la vigente "Ordenanza Fiscal Reguladora de la Tasa de Alcantarillado», en los mismos términos que se hace con el artículo 9 de la Ordenanza Fiscal de las Tasas por suministro de aguas potables y servicios complementarios-, lo que considera ilegal la actora y a cuya tal calificación se oponen los demandados.

Las tres premisas se contienen en el FJ cuarto, y son las siguientes: a) se trata de la impugnación directa de una disposición general, la Ordenanza Fiscal en cuestión, una de las modalidades de disposiciones generales de carácter local; b) estamos ante una normativa tributaria concretamente referida a una tasa municipal, en el ámbito del suministro y evacuación de aguas en una ciudad; c) en el supuesto de ser apreciada causa de nulidad, la sanción correspondiente será de nulidad radical en aplicación del art. 62.2 de la Ley 30/1992 (actual art. 47.2 de la Ley 39/2015). Esta última premisa es también anunciada en la sentencia del Supremo en su FJ tercero, aunque posteriormente, en el FJ sexto, se refiere a la causa de nulidad de pleno derecho relativa a los actos administrativos del art. 62.1.e (47.2.e de la Ley 39/2015), poniéndose énfasis así de algún modo en el aspecto esencial del procedimiento que supone el principal aspecto a comentar aquí, el de los informes técnico-económicos, como veremos. 
Los dos razonamientos clave se encuentran en el FJ quinto de la Sentencia del TSJ-CyL. Uno es de carácter general y el otro se cińe al supuesto particular. Ambos parten del carácter preceptivo de los informes técnico-económicos en la imposición de tasas. El primero afirma que resulta admisible, tanto que tales informes sean elaborados fuera de la Administración (pese a que, se dice, quizá el sentido inicial de la ley en este punto sea el de que los sujetos que los redacten materialmente sean técnicos de la Administración) y asumidos, eso sí, por los expertos de la Administración, como que dichos informes puedan ser completados o subsanados con alguna otra actuación posterior en aquello que pudieran tener de incompletos o defectuosos. Dicho esto, el segundo razonamiento consiste en afirmar con claridad que en el caso controvertido, el informe aportado el mismo día de adopción de los acuerdos era un informe privado - de la concesionaria - no asumido ni verificado por empleados públicos y por ello sin la nota de objetividad propia de la actuación administrativa, y cuya incorporación choca de modo frontal con el derecho de los ediles a conocer íntegramente el objeto de la votación. Siendo así que los previos informes de los técnicos municipales instaban la aportación de nuevos informes que justificaran adecuadamente la decisión, se trató de subsanar extemporáneamente la insuficiencia de tales informes de la concesionaria.

Todo ello implica el sentido parcialmente estimatorio de la sentencia del TSJ-CyL, con la excepción del incremento de tarifas general del 1,5\%, dado que según la legislación aplicable no era en este aspecto exigible memoria técnica y además, paradójicamente, aquí sí se produjo pronunciamiento favorable de concesionaria y empleados municipales.

Con ello llegamos a la Sentencia del Supremo. Su FJ segundo desestima la incongruencia de la sentencia del TSJ-CyL, alegada por el Ayuntamiento de León, al considerar el Supremo que no es incongruente que la Sala de Valladolid estimara que los empleados municipales no asumieron la procedencia del informe de la concesionaria "con independencia de que formalmente [los testigos] no negasen de manera radical la procedencia de las modificaciones", pese a haber sostenido, como hemos visto, que es posible la elaboración externa de los informes (si son asumidos por los técnicos municipales). Algo que es premonitorio del tema clave, la insuficiencia de los informes en los términos que ahora desarrollamos.

Para concretar mejor los términos fácticos de esa insuficiencia, es útil indicar que el Supremo, en el FJ tercero, señala que, además del anteriormente citado informe de Aguas de León S.L., la concesionaria del servicio, de finales de 2013 — del que no tuvieron debido conocimiento los técnicos municipales ni tampoco los ediles-, hubo, es cierto, un primer informe también de dicha empresa. Y respecto a este primer informe, se aclara que: a) el jefe del Servicio de Asuntos Económicos no valoró su justificación económica 
por considerar concurrente una causa de incompatibilidad (al haber presentado reclamaciones en condición de secretario de una asociación de vecinos y comerciantes); b) el interventor del Ayuntamiento manifestó que no había tenido participación en la elaboración de ningún informe; y c) quien sí que examinó la justificación económica fue la adjunta al jefe del Servicio de Asuntos Económicos. Dicho examen puso de relieve, entre otros elementos, que el estudio económico era manifiestamente insuficiente y no soportaría la revisión judicial, por lo que sugería que se incorporara antes de la aprobación una memoria técnico-económica que justificara la cuantía de la tasa, poniendo de manifiesto la necesidad de reforzar los informes económicos.

De tal manera que en este mismo FJ el Supremo deja servida la pregunta clave, la "cuestión real» como él mismo la califica: si, a efectos del art. 25 del Texto Refundido de la Ley de Haciendas Locales (Real Decreto Legislativo 2/2004, precepto que exige el informe técnico-económico para los acuerdos de establecimiento de tasas), «es válido el Informe económico financiero emitido por la propia empresa adjudicataria del Servicio. Y, en particular, si es un requisito para la validez de la modificación de la ordenanza que el informe sea emitido o ratificado por técnicos municipales». La respuesta del Supremo es inmediata: el informe es un elemento esencial, un requisito insubsanable, su falta conlleva la nulidad de la ordenanza. Esto es algo que ya había establecido la jurisprudencia del TS.

Por eso, lo que destacamos en este caso es la siguiente afirmación que hace de inmediato, en este FJ tercero, la sentencia que comentamos, que por su importancia reproducimos:

La existencia del informe técnico-jurídico se exige como garantía para el administrado, ya que a la vista del mismo es como puede determinarse si la Administración ha fijado el importe de las tasas con arreglo a derecho (STS 18/03/2010). La elaboración de este informe por empleados del Ayuntamiento que estén cualificados para ello (bien el interventor o el técnico competente) es una garantía para el administrado por su presunción de imparcialidad. En nuestro caso este informe no ha sido elaborado por técnicos municipales sino por la propia empresa concesionaria del servicio y parte interesada. Y la Adjunta al Jefe de Asuntos Económicos ha dicho que en algunos casos no existe y que en el resto el informe es insuficiente y que debe ser reforzado. Habiéndose tomado por el Pleno el acuerdo definitivo sin tener en cuenta que el informe de Aguas de León no ha sido asumido por ningún técnico municipal.

Esta afirmación se complementa perfectamente con esta otra que también conviene reproducir, esta vez en el FJ séptimo y en respuesta a la sociedad concesionaria: 
El establecimiento de nuevas tasas exige la existencia de un verdadero Informe técnico-económico. Además este informe no puede ser elaborado por personal ajeno al Ayuntamiento en el que el técnico municipal no aporte ningún dato de comprobación y justificación de lo facilitado por la empresa adjudicataria del servicio, que es parte interesada. El cálculo de las tasas se hace con datos interesados y de la propia sociedad, sin comparación alguna con datos del mercado como exige la ley. No debe obviarse, además, que queda al arbitrio de la propia sociedad suministradora del servicio decidir cuándo procede o no la conservación de las acometidas concretas. La Sociedad Mixta Aguas de León, S.L. decide de esta forma el cómo, el cuándo y el precio de las reparaciones a realizar, basándose en sus propios antecedentes, y sin introducir datos de competencia y mercado, cuando es generalmente admitido que la ausencia de competencia se considera una de las causas fundamentales de las deficiencias de los servicios públicos.

Queda bien claro. Dado que del proceso de instancia se deduce con toda claridad - excluyendo toda tacha de incongruencia alegada por las recurrentes en casación- que no ha existido informe técnico-económico ni elaborado ni ratificado por técnicos municipales y que tal informe en dichos términos es preceptivo en orden a la validez de la modificación de la ordenanza — dado que también es preceptivo no solo en acuerdos de establecimiento de tasa, sino también de cualquier modificación de las cuotas tributarias - se produce el vicio ya apreciado por el TSJ-CyL.

Hemos dicho al introducir el caso que este supuesto encuentra un perfecto contexto de afirmación en el ámbito concreto en que se produce (justificación económica de unas tasas municipales), pero que lo trasciende. Veamos brevemente a qué nos referimos concretamente.

\section{EL CARÁCTER PRECEPTIVO DEL INFORME TÉCNICO-ECONÓMICO}

En primer lugar, el contexto de afirmación es el del carácter preceptivo, fundamental, sagrado, del informe técnico-económico, partiendo del mencionado art. 25 del TRLHL, así como del art. 20 de la Ley 8/1989, de Tasas y Precios Públicos. Este segundo precepto establece la memoria económicofinanciera como elemento preceptivo en toda propuesta de establecimiento de nueva tasa o modificación de cuantías, hace referencia a su contenido de justificación de la cuantía propuesta y establece que su falta determinará la nulidad de pleno derecho de las correspondientes disposiciones reglamentarias.

La jurisprudencia ha reafirmado sin ambages este carácter preceptivo y fundamental. Así, la STS de 1 de julio de 2003 (rec. 8493/1998, ponente: Rouanet Moscardó), en un caso relativo a prestación de servicios de gestión y recaudación del Ayuntamiento de Bembibre, señaló - FJ 3- que el estudio 
económico financiero no es un mero requisito formal y su inexistencia provoca fatalmente la nulidad de la ordenanza. La STS de 18 de marzo de 2010 (rec. 2278/2004, ponente: Martínez Mico), como hemos visto, citada en la que comentamos, relativa a las ordenanzas fiscales para 2001 del Ayuntamiento de Jaraíz de la Vera, que no dejó de indicar la sustancial identidad material entre informe técnico-económico y memoria económica financiera a las que se refieren los dos textos legales que hemos citado aquí, señala que dicha memoria tiene que estar presente de manera inexcusable para la aprobación provisional de la ordenanza, sin ser posible la subsanación de su omisión con la elaboración para la aprobación definitiva. También citaremos la STS de 24 de febrero de 2014 (rec. 3721/2010, ponente: Fernández Montalvo), asimismo mencionada por nuestra sentencia. La de 2014 es una de las sentencias de referencia en lo que concierne al nivel concreto de precisión exigible de la justificación en la memoria económico-financiera de las concretas previsiones en aquel caso en el ámbito del Consorcio para el tratamiento de residuos sólidos de la provincia de Burgos, con la impugnación del Ayuntamiento de Miranda de Ebro. De esta sentencia podemos destacar a modo de síntesis la siguiente afirmación -FJ 4-: «En consecuencia, resulta imprescindible justificar no solo el coste total del servicio sino también los criterios, módulos o índices que sirven para la individualización del tributo conforme a su propia naturaleza».

Además, muy a menudo esta abundante jurisprudencia pone de manifiesto que estos informes son una garantía del principio de equivalencia en materia de tasas, lo cual constituye un elemento más de específica necesidad de justificación reforzada. Esto también está presente en el caso de nuestra sentencia, que dedica buena parte de su contenido - FJ cuarto, sobre todotambién a analizar la cuestión del principio de equivalencia y provocación de costes, tema en el que ya advertimos que no vamos a entrar y al que en cambio no dedicó la misma atención la sentencia de instancia. Pero que por supuesto no debe ser ignorado en este contexto de rigor de la justificación económica.

En definitiva, podemos decir que existe una notable sensibilidad a diversos niveles o en diversas facetas en lo que sería la seriedad de estos informes o memorias. Seriedad en sentido material a la que esta sentencia ahora viene a confirmar lo fundamental de un dato como es la asunción real de su contenido por parte de los técnicos municipales. A ello volveremos ahora mismo. No sin antes subrayar dos pasajes más de la sentencia en esta línea, ambos contenidos en el FJ sexto: por un lado, se remarca que el informe técnico económico debe realizarse teniendo en cuenta que la cuantía de la tasa propuesta, «exige una motivación especialísima», ante el riesgo de arbitrariedad que se podría producir en caso de no ser así, y en consonancia con el carácter exhaustivo de esa justificación económica en la línea de lo afirmado por la sentencia de 2014, entre otras. Por otro lado, la sentencia también afirma que: 
[...] cualquier modificación de la cuantía de las tasas precisará de la necesaria justificación con la elaboración de informes que deben de ser realizados de forma rigurosa y completa y no meros simulacros. En otro caso acarrearía la nulidad de la modificación de la Ordenanza y de las liquidaciones giradas a su amparo. Y esto entendemos es lo que ha ocurrido en nuestro caso. Pues, además de que las únicas memorias económico-financieras son de la sociedad Aguas a quien corresponde la prestación del servicio, las mismas no se han realizado de forma exhaustiva ni reflejan la imagen fiel de la modificación que se pretende. Dichos informes deben de responder a técnicas económicas, estadísticas y financieras.

De modo que en el contexto de esa seriedad cualificada de estos informes se explica la necesidad de contar con informes que además de ser completos y rigurosos (la misma sentencia comentada se refiere en el FJ tercero a que «la omisión no viene determinada sólo por la total inexistencia de unos documentos calificados como tales informes, sino también por la falta de un mínimo rigor en el planteamiento y formulación de los mismos»), rigurosos en su contenido y en el método, no sean de parte, sino asumidos por la Administración, como ahora remarcaremos, según hemos anunciado.

La sentencia trasciende a su ámbito concreto, con ser este muy importante, como hemos podido comprobar, y básicamente ello se concreta en la cuestión de la imparcialidad y objetividad administrativa. Antes de ir definitivamente a ello permítasenos siquiera apuntar que también existen otros ámbitos, como es bien conocido, en que la preceptividad y rigurosidad de los informes o memorias económico financieros vienen siendo últimamente remarcadas por el TS. Podríamos así recordar casos recientes en el ámbito urbanístico, como el de la STS 725/2016, de 31 de marzo (rec. 3376/2014, ponente: Peces Morate), en que se recuerda el carácter preceptivo del estudio económico financiero en toda clase de instrumentos de ordenación urbanística, con anulación del PGOU de El Campello (pese a que la legislación autonómica no disponga expresamente tal exigencia) o el de la Sentencia del Tribunal Superior de Justicia de Madrid 72/2017, de 3 de febrero (rec. 814/2015, ponente: Canabal Conejos), que anula el PGOU de Pedrezuela poniendo de manifiesto la insuficiencia de la memoria a efectos de justificar la adecuada ordenación del desarrollo urbano en varios aspectos.

Vemos, pues, cómo no deja de ocupar nuestra sentencia un lugar entre la jurisprudencia que remarca el necesario rigor de las memorias e informes técnicos, económicos y financieros en contextos donde es crucial su acierto en la formación de la voluntad de los órganos competentes y también para su adecuado tratamiento en términos de participación ciudadana. 


\section{EL INFORME DEBE SER PROPIO DE LA ADMINISTRACIÓN}

\subsection{Informe propio, objetividad e imparcialidad}

Pero, como hemos dicho, en este contexto la sentencia también trasciende especialmente por el elemento vinculado a la apreciación de la imparcialidad vinculada a la imposibilidad de hacer depender estos informes de meras aportaciones de parte sin contraste o asunción auténtica por parte de los empleados públicos con competencias en la materia. Volvemos, pues, sobre aquellos dos párrafos de los FFJJ tercero y séptimo antes reproducidos. En ellos se contiene una afirmación clave: la directa responsabilidad de los empleados públicos — sea en términos de elaboración propia o de asunción indubitada de informes de elaboración externa- es garantía clave en términos de imparcialidad y objetividad, principios fundamentales del art. $103 \mathrm{CE}$. Se comprometen esos principios clave de la actuación administrativa si no hay una comprobación y asunción real de los informes de parte. Es exigible, en definitiva, un criterio propio en la formación de la voluntad administrativa. Y ese elemento debe quedar claramente acreditado, de ahí que en caso de duda podemos entender que el Supremo confirma el criterio del TSJ-CyL cuando se alega incongruencia por poner en duda que los informes de la concesionaria realmente no fueran asumidos por los empleados públicos. Pese a alguna duda que pudiera ofrecer algún pasaje del relato, no hay constancia de una verdadera situación de ratificación. De modo que constatada esa situación fáctica, como se ha dicho, se considera viciado el procedimiento por falta de un informe en las condiciones exigibles. Elemento que se acentúa adicionalmente diciéndose (FJ tercero) que:

Hay una corriente doctrinal que, incluso, exige que los datos del informe técnico-económico deberían certificarse por el Interventor, pues el Informe debe referenciarse a gastos e ingresos recogidos en la contabilidad e incluir costes como las amortizaciones y provisiones que si bien no suponen contabilidad presupuestaria deberían recogerse en la contabilidad municipal, por lo que en la medida que dichos datos son competencia de la Intervención Municipal éste debería intervenir [recordándose entonces que:] En nuestro caso el Interventor General del Ayuntamiento declaró que no tuvo intervención alguna en el expediente del establecimiento de nuevas tasas ni de modificación de las existentes.

Y no solo eso, sino que además la sentencia comentada ańade otro elemento más, que podríamos decir que pone de manifiesto una segunda situación de disconformidad con el principio de imparcialidad, y que podría dar lugar a un comentario monográfico por sí solo: esta situación «de segundo 
grado» insatisfactoria con tal principio se pone de relieve con la no participación del interventor. En el FJ séptimo se apunta esto:

Se dice por la entidad AGUAS DE LEÓN que el Interventor no intervino en la modificación de la Ordenanza, pero lo cierto es que el interventor no intervino en la tramitación de la creación de las nuevas tasas, pues no consta en el expediente ningún informe a este respecto. El hecho que sea Consejero de la Sociedad Mixta de Aguas no sustituye su labor como técnico municipal de informar en el expediente de aprobación de la Ordenanza para que los ciudadanos puedan tener conocimiento de su criterio. Más aún, cabe poner en duda la compatibilidad de ambos cargos, lo cual motiva también la impugnación de la modificación. La Ley de Sociedades de Capital en sus artículos 227, 228 y 229 establece unas obligaciones de los Administradores de las Sociedades que entran en conflicto con los intereses de los ciudadanos que como técnico municipal debe defender, pues no siempre coinciden los intereses generales con los de una sociedad de tipo capitalista donde el $49 \%$ del capital social pertenece a un particular que busca su propio beneficio y del que el interventor municipal es Consejero.

Aspecto que, por tanto, forma parte del contexto problemático de la situación y de cuya indicación cabe tomar nota por lo relevante del planteamiento, y que ahora simplemente señalamos.

\subsection{El caso de la «externalización» de las mesas de contratación}

Si hemos dicho que el aspecto de la protección de la imparcialidad trasciende este ámbito es porque no es el primero en que se producen pronunciamientos del TS en esta línea, formando así un conjunto jurisprudencial con un sustrato común que debe ser muy tenido en cuenta. Concretamente cabe referirse al supuesto de la actuación de las mesas de contratación como ámbito en el que se han producido este tipo de respuestas del TS y de otros tribunales. Casos en que se producía una valoración de las ofertas por parte de la mesa de contratación exclusivamente a través de informes encargados a empresas externas.

Tenemos así el caso de la STS de 18 de julio de 2012 (rec. 5128/2008, ponente: Martín de Hijas), en materia de adjudicación de concesiones en el ámbito audiovisual. El motivo del recurso consistente en la alegación de que la mesa no había cumplido la obligación de ponderar los criterios de valoración establecidos en las bases de la convocatoria del concurso se estima. El TS - FJ 11 - indica que tal función en realidad fue delegada o externalizada a una empresa, y aunque, con cierto paralelismo con nuestro caso, no niega la posibilidad de recabar asesoramiento externo, también afirma que ello no puede implicar 
sin más asumir tal valoración dándola por buena, dado que la función de valoración es «propia e indelegable». La sentencia establece así una correlación entre discrecionalidad técnica y órgano compuesto por personas de la Administración con conocimientos especializados, presunción de acierto y legalidad, garantías de objetividad e imparcialidad no propias de una entidad privada y posibilidades legales de recusación. Una cosa es, pues, que la mesa, a partir de una opinión externa, la matice, module o corrija, sirviéndose de ella para hacer su propia valoración, y otra cosa es simplemente delegar esa función sin más, con simple asunción de la puntuación numérica otorgada por la consultora privada (que es cosa distinta a la ponderación, que supone algo más que la mera puntuación, como se encargó también de dejar claro la STS de 20 de marzo de 2012, rec. 1293/2009, ponente Murillo de la Cueva, FJ 7).

En la misma línea de no discutir la facultad de la Administración de recabar todo tipo de informes pero sí negar la posibilidad de aceptarlos de manera acrítica se había pronunciado también la STS de 25 de junio de 2012 (rec. 717/2009, ponente: Murillo de la Cueva, FJ 6), también en un supuesto de concesiones en el ámbito audiovisual. Muy interesantes fueron en este caso los fundamentos jurídicos de la sentencia de instancia, confirmada por el TS, la STSJ de Canarias de 5 de diciembre de 2008 (rec. 866/2007, ponente: Varona Gómez-Acedo). No podemos dejar de reproducir aquí un extracto de su FJ cuarto:

Así el art. 82 y 83 de la Ley 30/92 de PAC incluye la petición y evacuación de informes dentro de las disposiciones que regulan el procedimiento administrativo, procedimiento que está ordenado a la formación de la voluntad de la Administración y que en consecuencia se realiza por la concurrencia de los distintos órganos llamados a conformar dicha voluntad que se terminará expresando en el acto Administrativo final. Solo la observación de tales reglas permitirá proclamar la final validez del acto administrativo. Por idéntica razón debe asimismo afirmarse que los informes técnicos que recabe la Mesa de contratación deben ser realizados por los propios servicios técnicos con que cuenta la Administración y solo en los casos en que quede acreditado que tales servicios no existen o son insuficientes, podría acudirse a asesoramientos externos. Entenderlo de otra forma sería desnaturalizar la propia existencia de la Administración constitucionalmente concebida para servir con objetividad los intereses generales en la forma que se contiene en el art. 103 CE. No existe la posibilidad de que los titulares de las potestades administrativas acudan a su libre albedrío a los órganos de la Administración o a otros externos según pueda en cada caso convenirles. Ello implicaría por sí mismo un ejercicio arbitrario de tales potestades. En el caso de que efectivamente se justifique la necesidad de acudir empresas o profesionales de consultoría y asistencia técnica externa a la Administración deberá realizarse su selección a través de procedimientos 
que garanticen al menos los principios de publicidad y concurrencia mediante el oportuno expediente de contratación. En cualquier caso la Mesa de Contratación no puede hacer dejación total de sus funciones remitiéndose sin más al contenido de tales informes. Deberá realizar al menos una mínima valoración crítica que exteriorice las razones que le llevan a aceptar el informe y transformarlo en su propia propuesta.

\section{INFORME TÉCNICO-ECONÓMICO Y EJERCICIO DE FUNCIONES PÚBLICAS}

Vemos cómo hay un sustrato común en aceptar la ilustración a través de informes, también externos - aunque en el caso de esta última sentencia con condicionantes a la hora de decidir ese recurso a elementos externos que habrá que seguir explorando- - en rechazar en todo caso un desapoderamiento en el ejercicio de funciones que solo a la Administración y a su personal competente incumben. Entre ambos puntos, hay un territorio en el que caben matices y se podrían formular opiniones diversas, y en el que es importante manejar con cuidado los términos. Ya hemos visto que cada contexto particular significa un entorno concreto de condiciones; pero ese sustrato común existe. Un sustrato común en cuya importancia no hace falta insistir. Está en juego el auténtico entendimiento de los principios de profesionalidad, imparcialidad y objetividad de las administraciones públicas.

Evitar la captura de intereses y/o la dejación de ejercicio de funciones propias pasa por llenar de contenido lo que sería el requerimiento sustancial de estos principios: que la valoración sea propia, que exista un criterio propio y responsable, que no se vacíen de contenido con meros formalismos las verdaderas tareas que implica el ejercicio de las competencias. Ese sería el límite en todo caso a la posibilidad de «asumir» o «ratificar» informes ajenos, el de contrastarlos, verificarlos, cuestionarlos, valorarlos con criterio propio.

En definitiva, tal vez lo que se esté planteando en el fondo es determinar si existe, en realidad, una función pública, «reservada» a la Administración —no se trata ahora de cuerpos y de habilitaciones - y cuál es su alcance, en este tipo de actuaciones. Hemos visto cómo la STS recordaba que la «Ley de Sociedades de Capital en sus arts. 227, 228 y 229 establece unas obligaciones de los Administradores de las Sociedades que entran en conflicto con los intereses de los ciudadanos que como técnico municipal debe defender [el interventor ]». Hay sin duda una responsabilidad de «servicio objetivo del interés general» que corresponde a la Administración como institución y que debe desarrollar mediante personal propio. La prohibición de ceder mediante contrato las funciones «de autoridad» que recoge nuestra legislación encontraría un claro 
ejemplo en este caso. No se olvide que el informe técnico-económico municipal, siendo un acto de trámite — cualificado— está dotado de presunción de legalidad, luego de autoridad.

Las anteriores consideraciones adquieren mayor sentido, aún, al situar el informe técnico-económico a que nos venimos refiriendo en el ámbito del ejercicio de la potestad normativa municipal. Potestad de ordenanza fiscal de significado restrictivo de derechos, en la medida que implica el establecimiento de obligaciones y cargas para el ciudadano. La limitación de dicha potestad mediante elementos reglados como el informe de referencia incrementa la relevancia de su correcto ejercicio, del que depende, en definitiva, la validez de la norma impositiva.

Algo en lo que, por obvia que sea en el fondo su exigencia, deberá seguir insistiendo y perfilando la futura jurisprudencia a la que cabrá seguir atentos en estos y en otros ámbitos (FR y TF).

\section{UN PASO MÁS EN EL CONTROL JUDICIAL DE LA EXISTENCIA DE SUFICIENTES RECURSOS HÍDRICOS PARA NUEVAS DEMANDAS PREVISTAS POR EL PLANEAMIENTO URBANÍSTICO}

Es conocida la jurisprudencia que declara la nulidad de los planes urbanísticos por no garantizar la suficiencia de recursos hídricos para nuevos desarrollos urbanísticos. La finalidad principal perseguida ha sido reforzar el informe del organismo de cuenca en aquellos casos en que se había omitido, o bien era desfavorable.

La Sentencia del Tribunal Supremo de 17 de febrero de 2017 (sección 2a, RCA 1125/2015, ponente: Rafael Fernández Valverde) es novedosa porque aplica esta jurisprudencia a un nuevo supuesto de anulación de un plan urbanístico por falta de suficiencia de recursos hídricos. En este caso existía un informe favorable del organismo de cuenca, pero no se considera suficiente porque no se disponían aún de las correspondientes concesiones en el momento de aprobación del plan urbanístico, sino que se encontraban en trámite. Por ello, el Tribunal Supremo declara haber lugar al recurso de casación y anula la Sentencia del Tribunal Superior de Justicia de Galicia de 21 de enero de 2016 que había desestimado el recurso contencioso-administrativo contra la aprobación definitiva del Plan General de Ordenación Urbanística del municipio de Verín (Orense), así como también estima este recurso contenciosoadministrativo y anula dicho Plan.

A continuación, nos vamos a centrar únicamente en la alegación sobre la falta de suficiencia de recursos hídricos porque es la más relevante y en la que hay una frontal discordancia entre el Tribunal Supremo y el Tribunal Superior 
de Justicia de Galicia. No obstante, señalamos que la sentencia desestima otras alegaciones que el Tribunal Superior también había rechazado relativas al momento de la entrada en vigor de una ley autonómica, la reiteración del trámite de información pública del Plan General de Ordenación Urbanística por modificaciones sustanciales, la insuficiencia del estudio económico financiero y del informe de sostenibilidad económica o la carencia del preceptivo resumen ejecutivo.

La Sentencia del Tribunal Superior de Justicia de Galicia de 21 de enero de 2016 desestimó la alegación de falta de suficiencia de recursos hídricos porque constata que, después de un primer informe desfavorable de la Confederación Hidrográfica del Duero, existen hasta tres informes favorables de dicho organismo público que manifiestan, de forma clara y expresa, la disponibilidad de recursos hídricos. Es más, afirma que el demandante confunde la existencia y la disponibilidad cuyos concretos significados son brevemente descritos en base a la STS de 21 de mayo de 2015 (RCA 2610/2013) en los siguientes términos: a) la suficiencia hace referencia a «la existencia de recursos hídricos bastantes», y b) la disponibilidad se concreta en «la posibilidad de aplicar los recursos hídricos existentes a la actuación urbanística en cuestión, lo cual requiere del correspondiente título administrativo concesional». Y entiende que la existencia de agua suficiente y la posibilidad de su aprovechamiento (con título) se deriva con claridad de los informes de la Confederación Hidrográfica. En este sentido, aclara que una cosa es que la disponibilidad (jurídica) dependa de los expedientes de concesión que están en trámite y otra, distinta, que no exista agua suficiente para satisfacer las nuevas demandas.

En cambio, el fundamento de derecho octavo de la Sentencia del Tribunal Supremo rechaza el razonamiento anterior y, como ya hemos avanzado, entiende que no hay suficiencia de recursos hídricos para los nuevos desarrollos urbanísticos previstos. Veamos cuál es la argumentación esgrimida.

En primer lugar, destacamos que se basa en la jurisprudencia del Tribunal Supremo, en muchas ocasiones, del mismo ponente Rafael Fernández Valverde y que se reproduce in extenso. En particular, parte de la STS de 12 de diciembre de 2016 (RCA 3137/2015) en un caso donde el informe de la Confederación Hidrográfica no se pronunció en sentido favorable ni desfavorable, limitándose a consignar la existencia de recursos hídricos y su no disponibilidad al no estar legalizadas determinadas captaciones previstas. A su vez, esta sentencia reproduce otra de 14 de noviembre de 2014 (RCA 2419/2012) en la que no se emitió informe de la Confederación Hidrográfica. A partir de ahí, sintetiza los siguientes argumentos principales.

Primero, el informe de la Confederación Hidrográfica es preceptivo en aplicación del art. 25.4 del Real Decreto Legislativo 1/2001, de 20 de julio, por el que se aprueba el Texto Refundido de la Ley de Aguas - TRLA— (en la 
redacción dada al mismo por la disposición final primera de la Ley 11/2005). Considera que el informe no queda condicionado a que esté previsto reglamentariamente, tal como establece ab initio dicho precepto para determinadas materias mencionadas a título ejemplificativo. Entiende que el informe resulta directamente exigible porque el mismo texto legal específica, de forma precisa, clara y rotunda, el supuesto concreto relativo a actos o planes de las comunidades autónomas o de las entidades locales que comporten nuevas demandas de recursos hídricos. Adicionalmente, puntualiza que este carácter preceptivo se ve reforzado por el hecho de que el informe se entenderá desfavorable si no se emite en plazo.

Segundo, además el informe de la Confederación Hidrográfica es vinculante, en virtud del apdo. 4 de la disposición adicional $2^{\text {a }}$ de la Ley 13/2003, de 23 de mayo, reguladora del contrato de concesión de obras públicas. Rechaza hacer una interpretación restrictiva que limite el alcance de los informes vinculantes estatales al estricto ámbito de las obras públicas de interés general y de competencia estatal (art. 149.1.24 CE). Ello lo justifica en base que este apdo. 4, a diferencia de los anteriores, se extiende genéricamente a cualesquiera procedimientos de aprobación, modificación o revisión de los instrumentos de planificación territorial y urbanística que puedan afectar al ejercicio de las competencias estatales (en este caso, el ámbito competencial de la Confederación Hidrográfica).

Indica que a ello no es óbice que el art. 15.3 del Real Decreto Legislativo 2/2008, de 20 de junio (actualmente, art. 22.3 Real Decreto Legislativo $7 / 2015$, de 30 de octubre, por el que se aprueba el texto refundido de la Ley de Suelo y Rehabilitación Urbana) no caracterice el informe sobre suficiencia de recursos hídricos como vinculante, sino como determinante, admitiendo la posibilidad de disentir del mismo de forma expresamente motivada. Recuerda que la jurisprudencia ha interpretado que este informe determinante es, sin ambages, vinculante en base a dos motivos: a) su valor reforzado que hace que, si bien no puedan caracterizarse como vinculante desde un plano formal, sí que se aproxima a ese carácter desde el plano material o sustantivo; y b) la posibilidad de apartarse motivadamente del informe no es absoluta ni incondicionada, sino que ha de moverse dentro de los límites marcados por el ámbito de competencia de la Administración (autonómica en este caso) que resuelve el expediente y no puede basarse en consideraciones que excedan de ese ámbito e invadan lo que solo a la Administración del Estado corresponde valorar.

Tercero, en relación al contenido del informe, manifiesta que, según el art. 25.4 TRLA, es claro que el informe de la Confederación Hidrográfica debe pronunciarse expresamente sobre la existencia o inexistencia de recursos suficientes para satisfacer nuevas demandas de recursos hídricos. La sentencia 
del Tribunal Supremo que comentamos perfila aún más dicho contenido. Se hace eco de cómo la jurisprudencia ya había desglosado dos manifestaciones de la suficiencia de recursos existentes: constatación técnica de la existencia de recursos hídricos y disponibilidad en el sentido de ordenación jurídica de los títulos de aprovechamiento (de su obtención, disponibilidad y compatibilidad). Así como también que la jurisprudencia había exigido que estas dos vertientes fácticas (existencia) y jurídicas (disponibilidad) de la suficiencia de recursos hídricos debían cumplirse en el momento de aprobación del plan urbanístico. En el caso de la citada STS de 12 de diciembre de 2016 (RCA 3137/2015), recordamos que el informe de la Confederación Hidrográfica no se pronunciaba en sentido favorable ni desfavorable, sino que se limitaba a consignar la existencia de recursos hídricos y su no disponibilidad al no estar legalizadas determinadas captaciones previstas. Y en el caso de la STS de 10 de marzo de 2015 (RCA 258/2013), mencionada en este apartado sobre el contenido del informe, la Confederación Hidrográfica había emitido un informe desfavorable y además no se consideró suficiente el convenio entre el ayuntamiento y la empresa promotora sobre caudal suficiente porque contenía actuaciones proyectadas para satisfacer necesidades hídricas en un futuro.

En cambio, en el presente caso, como ya hemos dicho, hay tres informes de la Confederación Hidrográfica en sentido favorable, pero se niega virtualidad a los mismos por considerar que, a pesar de la existencia de recursos hídricos, no hay una disponibilidad jurídica porque las concesiones previstas están en tramitación en el momento de aprobación del plan.

En fin, se puede criticar que la sentencia hace una interpretación muy restrictiva del requisito de la existencia de recursos suficientes para satisfacer nuevas demandas de recursos hídricos al exigir que se dispongan de las concesiones en el momento de aprobación del plan urbanístico. Pero entendemos que se trata de una necesaria interpretación no formalista de la norma que pretende dar una respuesta a los abusos que se han producido en los numerosos casos de crecimiento urbanístico desenfrenado (AP). 
